\title{
Evidence for Serotonin Synthesis, Uptake, and Release in Dissociated Rat Sympathetic Neurons in Culture
}

\author{
Dinah W. Y. Sah and Steven G. Matsumoto \\ Department of Neurobiology, Harvard Medical School, Boston, Massachusetts 02115
}

In the previous paper (Matsumoto et al., 1987), pharmacological evidence for secretion of serotonin (5-HT) by cultured sympathetic principal neurons was reported. Here, we present further evidence that 5-HT is a transmitter of some of these neurons under certain culture conditions, and can also be a "false" transmitter. Sympathetic principal neurons, dissociated from superior cervical ganglia (SCG) of newborn rats, were grown in cell culture. The presence of serotonin was demonstrated with high-performance liquid chromatography (HPLC), immunocytochemistry, and electrophysiological recording. Homogenates of cultures contained a substance that comigrated with authentic 5-HT in HPLC. A voltammogram for this substance was superimposed upon that for authentic 5-HT. When the cultures were examined with immunocytochemical staining, using the peroxidase-antiperoxidase technique, many neuronal processes contained 5-HT-like immunoreactive material. Many somata also contained 5 -HT-like immunoreactivity when the neurons were grown in the presence of medium conditioned by heart cells (CM), but few somata stained above background in the absence of CM.

Medium that contained a raised concentration of $\mathrm{K}^{+}(54$ mM) or veratridine evoked $\mathrm{Ca}^{2+}$-dependent release of 5-HT, consistent with a neurotransmitter role for 5-HT in the cultures. In preliminary electrophysiological experiments on microcultures containing single sympathetic principal neurons and cardiac myocytes, a nonadrenergic excitatory (NAE) interaction was sometimes obtained after exposing the neurons to $100 \mu \mathrm{m}$ 5-hydroxytryptophan. This interaction was sensitive to the serotonin blockers reserpine, methysergide, and gramine.

Of major interest in this paper was determining the source of the 5-HT in the cultured principal neurons. Evidence was obtained for uptake from the rat serum added to the medium, as has long been known in vivo. Moreover, evidence was obtained that after growth in CM (which promotes cho-

Received May 2, 1986; revised Aug. 18, 1986; accepted Aug. 19, 1986.

We thank the Marine Biological Laboratories and Bioanalytical Systems for providing the facilities and equipment for some of the HPLC experiments, and Chi-bin Chien and Dr. Joseph Carnwath for taking part in these experiments as part of the summer Neurobiology Course. We are indebted to Dr. Barbara Batelle for advice and guidance on the use of HPLC. We thank Drs. E. J. Furshpan, Story I andis, Rae Nishi, and David Potter for helpful advice and suggestions, Drs. Keiko Fukada, Margaret Livingstone, and Paul Patterson for comments on the manuscript, and Dr. Allison Doupe, Philip Hamilton, Margaret Thompson, and Dr. Eve Wolinsky for provinding NGF. This work was supported by an NSF predoctoral fellowship to D.S., NIMH Training Grant MH 18012, and NIH Grants NS 11576, NS 18316, NS 03273, and NS 02253.

Correspondence should be addressed to Dinah Sah, Department of Neurobiology, Harvard Medical School, 25 Shattuck Street, Boston, MA 02115.

Copyright $(1987$ Society for Neuroscience $0270-6474 / 87 / 020391-09 \$ 02.00 / 0$ linergic properties while suppressing adrenergic ones), some principal neurons synthesized ${ }^{3} \mathrm{H}-5-\mathrm{HT}$ from ${ }^{3} \mathrm{H}$-tryptophan; this occurred in cultures that lacked the small, intensely fluorescent interneurons that have been reported to contain $5-\mathrm{HT}$ in rat sympathetic ganglia in vivo.

With a sensitive microculture assay involving coculture of single sympathetic principal neurons with cardiac myocytes, neuronally evoked effects on the myocytes attributable to the release of norepinephrine, acetylcholine, and adenosine have been obtained (Furshpan et al., 1982; 1986a, b). Some microcultured neurons also exert nonadrenergic excitatory effects on the myocytes that last from 1 to several minutes, are $1-4 \mathrm{mV}$ in amplitude, and are insensitive to adrenergic, cholinergic, and purinergic antagonists (Matsumoto et al., 1987). In some of these cases, the NAE effect is sensitive to 5-HT antagonists; in other cases, an unidentified agent appears to produce the NAE effect (Matsumoto et al., 1987).

To examine further the possibility that 5 -HT is a neurotransmitter in these neurons, we have used biochemical methods to study its presence and release, and immunocytochemical methods to study its distribution. In addition, we present biochemical evidence that there are 2 major sources of neuronal 5-HT: synthesis and uptake from serum in the culture medium. We also present electrophysiological evidence that some neurons use 5-HT as a "false" transmitter after uptake from the medium, as has been previously reported in vivo (see Discussion). Interest in the synthesis of 5-HT by cultured sympathetic principal neurons is enhanced by a report by Häppölä et al. (1986) that some of these neurons transiently exhibit 5-HT immunoreactivity during postnatal development in vivo.

\section{Materials and Methods}

Cell culture. For biochemical and immunocytochemical experiments, "mass cultures" of dissociated sympathetic neurons (1000-3000 neurons per dish) were prepared as described in detail by Wolinsky and Patterson (1983). In brief, superior cervical ganglia (SCG) of newborn rats (Sprague-Dawley) were dissociated enzymatically, using collagenase ( $1 \mathrm{mg} / \mathrm{ml}$; Worthington) and dispase ( $4 \mathrm{mg} / \mathrm{ml}$; Boehringer-Mannheim), or mechanically. The cell suspension was plated into bicarbonate-buffered L-15 growth medium, supplemented with glucose, glutamine, antibiotics, vitamins, additional nutrients, and nerve growth factor (NGF) (L-15 $\mathrm{CO}_{2}$; Hawrot and Patterson, 1979). During 3 of the first $7 \mathrm{~d}$ in culture, the growth medium also contained (at $10 \mu \mathrm{M}$ each) cytosine-1$\beta$-D-arabinofuranoside and sometimes 5-fluorodeoxyuridine and uridine (Sigma) to eliminate non-neuronal cells. In a few platings, the growth medium also contained these antimitotic drugs at every other feeding. The cultures were fed $2-3 \times$ per week. The neurons were grown in 3 types of medium, with or without $5 \%$ rat serum: (1) L- $15 \mathrm{CO}_{2}$ medium, (2) depolarizing growth medium ("high $\mathrm{K}^{+}$") with $20 \mathrm{mM} \mathrm{KCl}$ replacing an equal amount of $\mathrm{NaCl}$ (Walicke et al., 1977), and (3) $\mathrm{L}-15$ $\mathrm{CO}_{2}$ medium equivalent to $100-150 \%$ heart-cell-conditioned medium 
(CM). The serum-free CM was prepared according to the method of Fukada (1980), and then concentrated 10 -fold by ammonium sulfate precipitation (Weber, 1981). This concentrated CM contained no detectable 5-HT or 5-hydroxytryptophan ( $<0.5 \mathrm{~nm})$, using HPLC with electrochemical detection (see below); serum-free L-15 $\mathrm{CO}_{2}$ medium equivalent to $150 \% \mathrm{CM}$ contained less than $0.07 \mathrm{nM} 5-\mathrm{HT}$ plus 5-hydroxytryptophan. Serum-free growth medium was supplemented with a mixture of hormones and nutrients devised by Wolinsky et al. (1985), based on the method of Bottenstein and Sato (1979): $100 \mu \mathrm{g} /$ $\mathrm{ml}$ transferrin (Sigma), $5 \mu \mathrm{g} / \mathrm{ml}$ bovine insulin (zinc salt; Sigma), $16 \mu \mathrm{g}$ / $\mathrm{ml}$ putrescine (free base; Sigma), 20 nм progesterone (Sigma), and 30 nM selenious acid (Baker). The cultures were used 2-12 weeks after plating.

Biochemical assays. For analysis by high-performance liquid chromatography (HPLC), 5-HT was extracted from sympathetic neuron cultures as follows. Cultures were rinsed $3 \times$ with PBS. Excess fluid was wicked away and replaced with $30 \mu \mathrm{l}$ of $0.05 \mathrm{M}$ perchloric acid containing $\alpha$-methyldopa (Sigma) or 3,4-dihydroxybenzylamine hydrobromide (Sigma) as an internal standard. After $3 \mathrm{~min}$ at room temperature, the cells were homogenized mechanically and then by rapid freeze/thawing twice. The resulting suspension was passed through a $0.2 \mu \mathrm{m}$ filter, and $20 \mu \mathrm{l}$ of the final solution was injected into the liquid chromatograph for analysis by reverse-phase HPLC with electrochemical detection. Absolute amounts of 5-HT were calculated from peak heights, with reference to the internal standard.

Separation was obtained using a $\mathrm{C}_{18}$ reverse-phase analytical column ( $5 \mu \mathrm{m}$; Biophase). Running buffer contained $0.1 \mathrm{M} \mathrm{NaH} \mathrm{PO}_{4} ; 0.1 \mathrm{~mm}$ $\mathrm{Na}_{2}$ EDTA; $2.5 \%, 10.2 \%$, or $12 \%$ (vol/vol) methanol; and, in some experiments, $0.25 \mathrm{~mm}$ sodium octyl-sulfate as an ion pair. All were buffered to $\mathrm{pH} 3.0$ with phosphoric acid and pumped at $1.0-1.3 \mathrm{ml} / \mathrm{min}$. The retention times for authentic 5-HT were determined under the various conditions. Serotonin was measured by electrochemical detection with an amperometric detector (Bioanalytical Systems) connected to a glassy carbon electrode. The potential of the working electrode was set at $0.60 \mathrm{~V}$ with respect to the $\mathrm{Ag} / \mathrm{AgCl}$ reference electrode.

To study 5-HT synthesis, the cultures were incubated with radioactive precursor, according to the method of Mains and Patterson (1973), with slight modifications. L [side chain-2,3-3 $\mathrm{H}$ ]-Tryptophan $(50$ or $54 \mathrm{Ci}$ / mmol) was obtained from Amersham and tested for radiochemical purity by HPLC with fraction collection. No contamination by 5 -HT was detected. The isotope was dried under a stream of nitrogen and redissolved in bicarbonate-buffered L-15 lacking tryptophan (Gibco), so that the final concentration of radioactive precursor was 3.7-4.0 $\mu \mathrm{M}$. All the additives in L-15 growth medium were present. Rat serum was added at $1 \%$ if the neurons had been grown in serum. In addition, the radioactive precursor was supplemented with nonradioactive tryptophan so that the total final concentration of tryptophan was $56 \mu \mathrm{M}$. Pargyline- $\mathrm{HCl}$ (Sigma) was included at $25 \mu \mathrm{M}$ in most experiments. The cultures were washed twice with $1 \mathrm{ml}$ growth medium lacking tryptophan, and then incubated $10 \mathrm{~min}$ at $36^{\circ} \mathrm{C}$ in this medium. This medium was removed and replaced with $150 \mu \mathrm{l}$ of medium containing radioactive tryptophan. The incubation was carried out for $17-18 \mathrm{hr}$ at $36^{\circ} \mathrm{C}$. At the end of the incubation, the incubation medium was wicked away and replaced with $2 \mathrm{ml}$ growth medium for $10 \mathrm{~min}$ at $36^{\circ} \mathrm{C}$. Most of this medium was removed, excess fluid was wicked away, and culture extracts were prepared for HPLC as described above. The extracts were injected into the liquid chromatograph, and $0.4 \mathrm{ml}(20 \mathrm{sec})$ fractions were collected and counted after the addition of $4 \mathrm{ml}$ Ultrafluor (National Diagnostics).

Transmitter release from the cultures was evoked by incubation with saline that contained $54 \mathrm{~mm} \mathrm{~K}^{+}$(instead of the normal $5 \mathrm{~mm}$ ) or veratridine $(75 \mu \mathrm{M})$, as follows. Cultures were rinsed $3 \times$ with nondepolarizing isotonic saline (defined below) at room temperature, then incubated (for $5 \mathrm{~min}$ each) in normal $\mathrm{Ca}^{2+}$ nondepolarizing isotonic saline, and then depolarizing isotonic saline (defined below). After each incubation, the medium was gently removed and filtered through a $0.2 \mu \mathrm{m}$ filter before injection into the liquid chromatograph for analysis. The 5-HT remaining in the culture was extracted by the procedure described above. To examine the $\mathrm{Ca}^{2+}$ dependence of release, cultures were rinsed and then incubated sequentially in the following media: nondepolarizing saline, high- $\mathrm{Mg}^{2+} / 0 \mathrm{Ca}^{2+}$ nondepolarizing saline (defined below), high$\mathrm{Mg}^{2+} / 0 \mathrm{Ca}^{2+}$ depolarizing saline, high- $\mathrm{Mg}^{2+} / 0 \mathrm{Ca}^{2+}$ nondepolarizing saline, nondepolarizing saline, and, finally, depolarizing saline. Again, the remaining 5-HT was extracted.

Nondepolarizing isotonic saline contained $5 \mathrm{~mm} \mathrm{KCl}, 140 \mathrm{~mm} \mathrm{NaCl}$, $3 \mathrm{mM} \mathrm{CaCl}_{2}$, and $1.5 \mathrm{~mm}$ HEPES, buffered to $\mathrm{pH} 7.4$ with Tris-OH.
Veratridine-depolarizing saline contained, in addition, $75 \mu \mathrm{M}$ veratridine-SO ${ }_{4}$ (Sigma). High- $\mathrm{K}^{+}$depolarizing saline contained $54 \mathrm{mM} \mathrm{KCl}$ and the above concentrations of other salts, except that $\mathrm{NaCl}$ was reduced to $90 \mathrm{~mm}$. Media with high $\mathrm{Mg}^{2+} / 0 \mathrm{Ca}^{2+}$ contained $3 \mathrm{mM} \mathrm{MgCl}$ in place of $\mathrm{CaCl}_{2}$.

Immunocytochemistry. For immunocytochemistry, cultures were treated with $100 \mu \mathrm{M}$ colchicine for 15-17 hr, rinscd with PBS scveral times, and then fixed with $4 \%$ paraformaldehyde in $0.12 \mathrm{M}$ phosphate

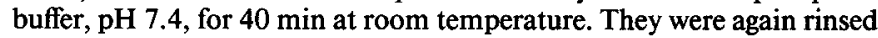
$3 \times$ with $P B S$, then incubated for $90 \mathrm{~min}$ at $37^{\circ} \mathrm{C}$ with a rabbit antiserum against 5-HT conjugated to BSA (Immunonuclear); the antiserum was diluted $1: 400$ or $1: 800$ in high-ionic-strength buffer $(0.5 \mathrm{M} \mathrm{NaCl}$ in 10 mu phosphate buffer at $\mathrm{pH} 7.4$ with $5 \% \mathrm{BSA}$, or $10 \%$ goat serum, $0.3 \%$ Triton $X-100$, and $0.1 \%$ sodium azide). Cultures were rinsed with highionic-strength buffer before incubation with the secondary antibody (goat anti-rabbit; Boehringer-Mannheim). Binding of the primary antibody was visualized using rabbit peroxidase-antiperoxidase (Sternberger-Meyer) with 3,3'-diaminobenzidine (Sigma). Preadsorption controls were run in parallel. Experimental and control cultures were photographed at the same exposure.

Electrophysiology. For electrophysiological experiments, single neurons dissociated from SCG of newborn rats were grown on cardiac myocytes in microcultures in the presence of $5 \%$ rat serum. They were examined electrophysiologically, as described by Furshpan et al. (1982, 1986a) and in the preceding paper (Matsumoto et al., 1987). During recording, the culture was continuously perfused at $37^{\circ} \mathrm{C}$. The perfusion medium contained $100 \mathrm{ml} / \mathrm{liter}$ basal L-15 medium and, in final concentrations (mM), $\mathrm{NaCl}, 140 ; \mathrm{KCl}, 5.4 ; \mathrm{CaCl}_{2}, 2.9 ; \mathrm{MgCl}_{2}, 0.18 ; \mathrm{Na}-$ $\mathrm{HCO}_{3}, 2.6 ; \mathrm{NaH}_{2} \mathrm{PO}_{4}, 0.56$; glucose, 33; glutamine, 2.0; and choline chloride, 0.07. In addition, penicillin was present at $200,000 \mathrm{U} /$ liter and streptomycin at $200 \mathrm{mg} /$ liter. Microelectrodes for intracellular recording and stimulation were filled with $3 \mathrm{M} \mathrm{KCl}$ and had impedances of 50-120 M . Drugs were obtained from the following sources: atenolol, Stuart Pharmaceuticals; phentolamine (Regitine-HCl), CIBA Pharmaceutical; 8-( $p$-sulfophenyl)-theophylline, Research Biochemicals; gramine, Sigma.

\section{Results}

\section{Identification of 5-HT in sympathetic neuron cultures}

Extracts of the cultures were examined with HPLC to determine whether they contained 5-HT. A peak with the same retention time as 5-HT was observed. Several chromatographic and electrochemical tests were performed to confirm that this peak represented authentic 5-HT. A coelution experiment is shown in Figure 1. The sample injected in Figure $1 a$ contained $0.23 \mathrm{ng}$ 5 -HT (retention time, $8.1 \mathrm{~min}$ ). In Figure $1 b$, a pooled extract from 9 cultures produced a peak with the same retention time as authentic 5-HT. When authentic 5-HT was added to the extract before injection, only a single peak of increased hcight was visible (Fig. 1c). In addition, when chromatographic conditions were varied with respect to methanol content and ion pair (see Materials and Methods), the 5-HT-like material extracted from the cultures had the same retention time as authentic 5-HT.

As a further test of the identity of the extract peak, a voltammogram was obtained by repetitive injection of aliquots of the same sample of culture extract while varying the potential of the working electrode. The profile for putative 5-HT from the cell extracts was superimposed upon that of the authentic compound (Fig. 2). The voltammogram for 5-hydroxytryptophol is shown for comparison (dashed line). On the basis of this evidence and further findings, reported below, it is assumed hereafter that the appropriate peak represents 5-HT in the cultures.

\section{The amount of 5-HT in the cultures depended on growth conditions}

Serotonin was present in cultures in appropriate growth conditions at all culture ages examined (2-12 weeks, 20 platings). 


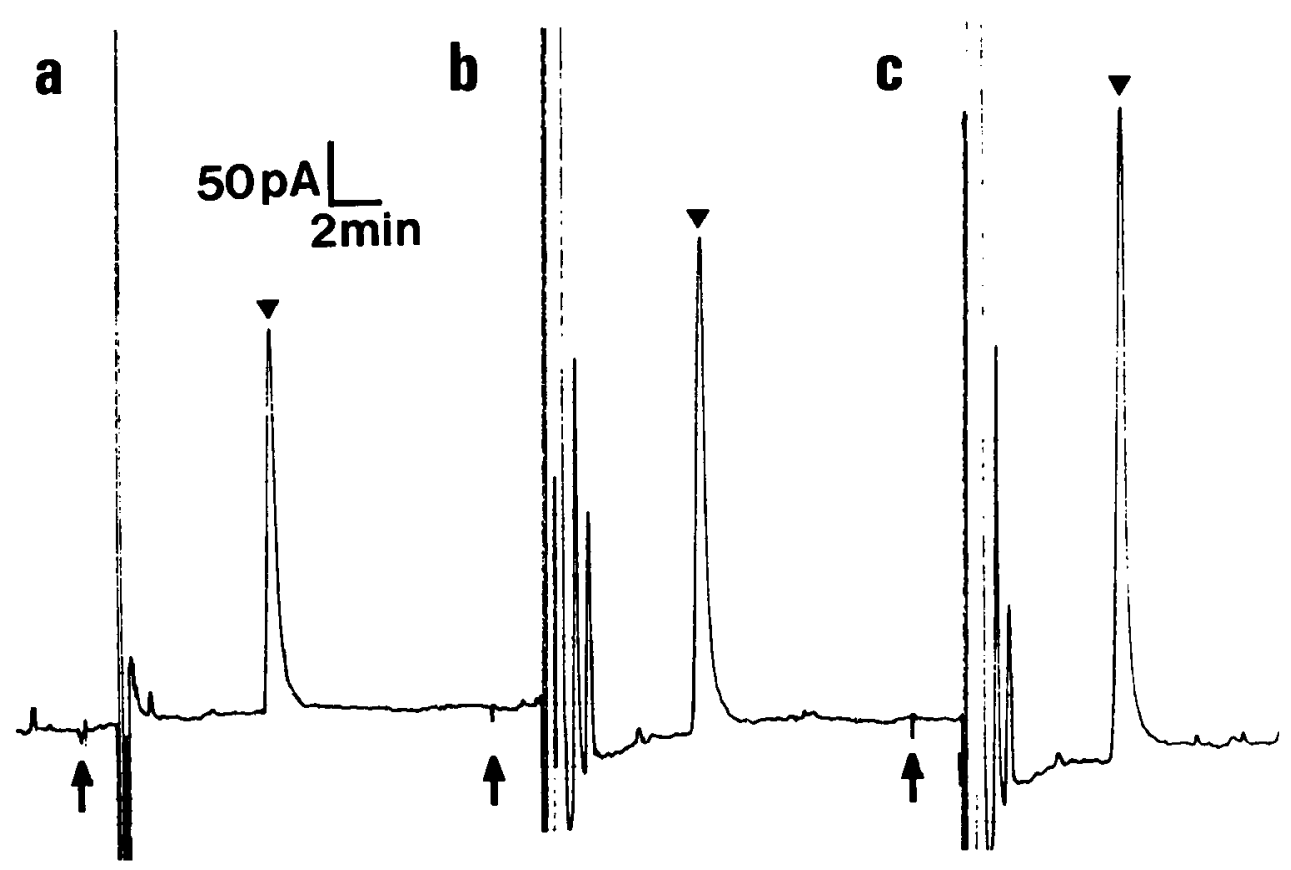

Figure 1. Coelution of authentic 5-HT and putative 5-HT extracted and pooled from 9 sympathetic neuron cultures $(3$ each grown in high $\mathrm{K}^{+}, \mathrm{L}-15 \mathrm{CO}_{2}$, and $\mathrm{CM}$, with $5 \%$ rat serum for $15 \mathrm{~d}$ ). $a$, Authentic 5-HT $(0.23 \mathrm{ng})$ was injected at the arrow, resulting in a peak at 8.1 min (arrowhead). $b$, An extract from sympathetic neuron cultures was injected, producing a peak with the same retention time as authentic 5-HT. c, A diluted sample of the culture extract was mixed with authentic 5 -HT $(0.23 \mathrm{ng})$ before injection; only 1 peak is visible. The running buffer was $0.1 \mathrm{M} \mathrm{NaH}_{2} \mathrm{PO}_{4}$ with $12 \%(\mathrm{vol} / \mathrm{vol})$ methanol.
The 5-HT in a single culture, containing approximately 2000 neurons, was measured by HPLC with electrochemical detection. The detection threshold of this method ranged from 0.03 to $0.16 \mathrm{pmol}$ of $5-\mathrm{HT}$. Levels of $5-\mathrm{HT}$ varied from $<0.2$ to 7.5 pmol per culture, depending on the type of growth medium and the time elapsed since the last exposure to fresh serum (see below). As summarized in Table 1, when neurons were grown in medium containing serum, relatively high levels of 5-HT were present; cultures grown in high $\mathrm{K}^{+}$(a medium that favors adrenergic status; see Walicke et al., 1977) contained more 5-HT than sister cultures grown in $\mathrm{L}-15 \mathrm{CO}_{2}$ or $\mathrm{CM}$ (media that induce cholinergic status; see Patterson and Chun, 1977a, and Wolinsky and Patterson, 1983). It was found that cultured neurons could take up 5-HT that was present in the serum that had been added to the growth medium (see below). To eliminate this uptake, neurons were grown in serum-free medium; then only the cultures grown in CM contained detectable amounts of 5-HT (Table 1). These cultures were used to construct the voltammogram shown in Figure 2; thus, cultures grown with $\mathrm{CM}$ in serum-free medium contained authentic 5-HT. The 5-HT precursor, 5hydroxytryptophan, was not detected in the cultures. In contrast, 2 putative metabolites were observed. A substance that had the same retention time as 5-hydroxy-3-indole acetic acid was present at levels ranging from $<0.05$ to $1.2 \mathrm{pmol}$ per culture (data not shown). In addition, a substance that comigrated with another 5-HT metabolite, 5-hydroxytryptophol, was present in the medium in which the neurons had been grown (data not shown).

To compare the amount of endogenous 5-HT to that of en-

Table 1. Serotonergic characteristics of neurons grown in the presence or absence of serum

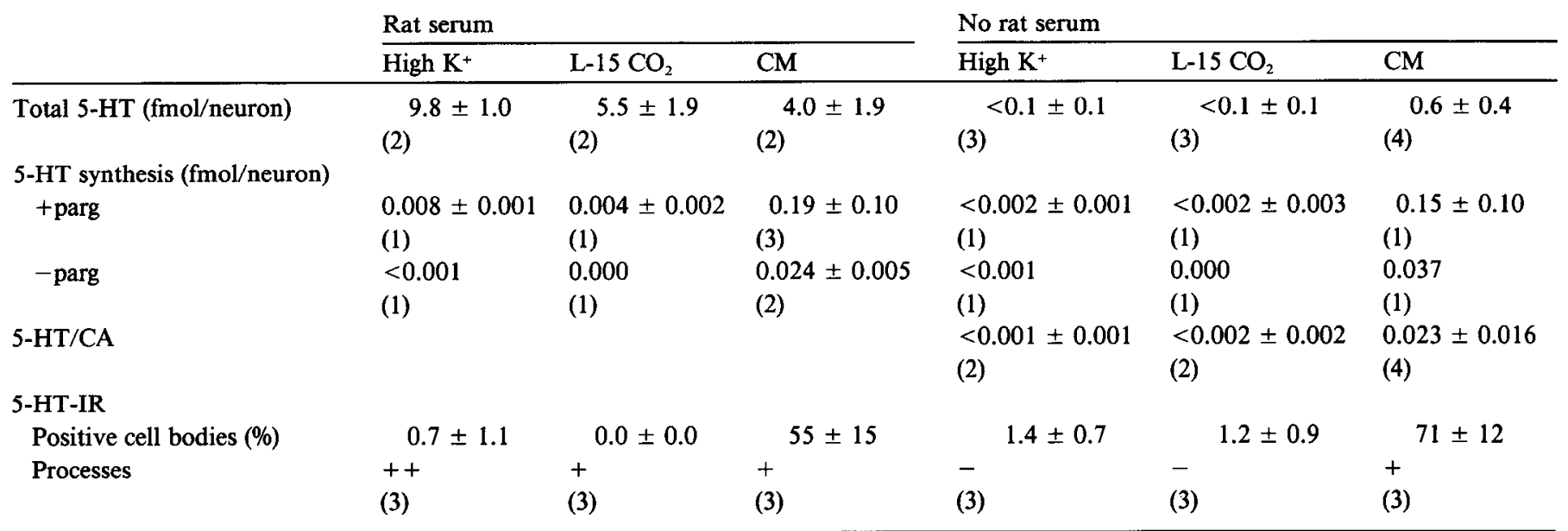

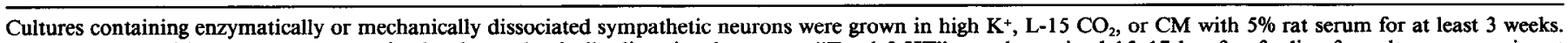

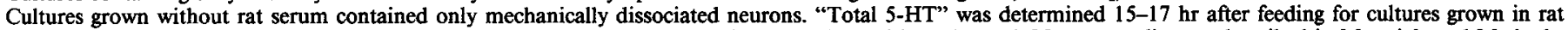

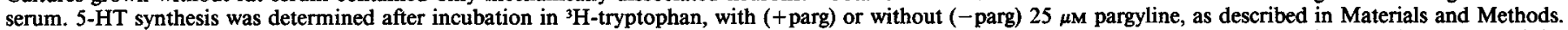

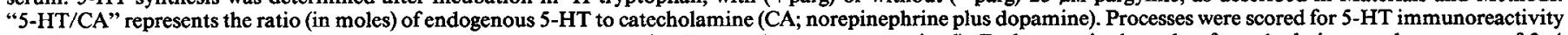

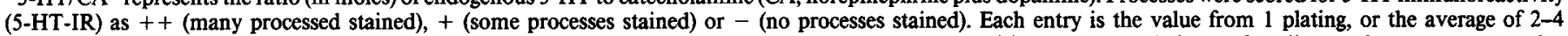
platings, \pm the standard deviation. The number of platings is shown in parentheses for each growth condition. For each plating, $1-5$ replicate cultures were assayed. 


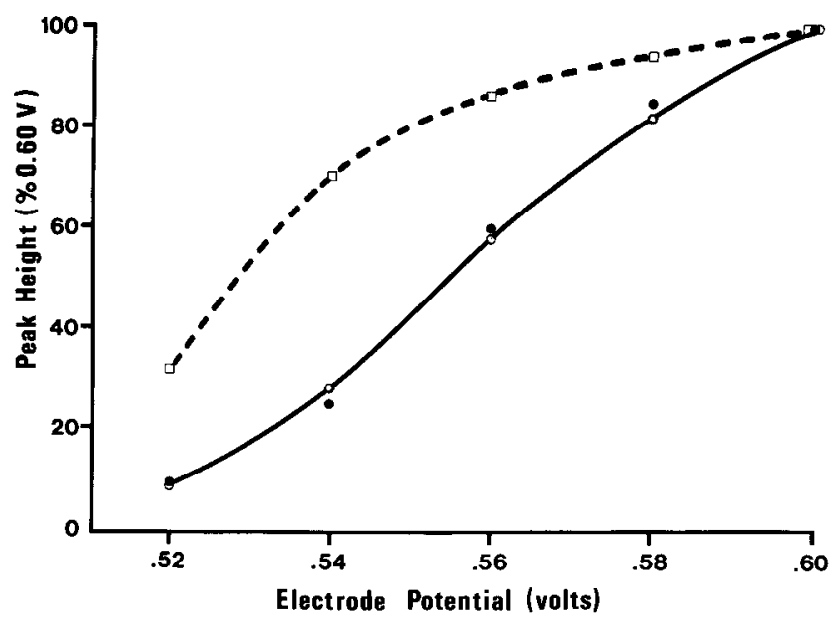

Figure 2. Voltammograms for authentic 5-HT (open circles) and 5-hydroxytryptophol (open squares), and putative 5-HT (closed circles) extracted and pooled from 30 sympathetic neuron cultures grown with $\mathrm{CM}$ in serum-free medium for $20 \mathrm{~d}$. Each point represents the average of 2 samples of pooled extract, except that for $0.56 \mathrm{~V}$, which represents 1 sample. The running buffer was $0.1 \mathrm{M} \mathrm{NaH}_{2} \mathrm{PO}_{4}$ with $10.2 \%(\mathrm{vol} / \mathrm{vol})$ methanol and $0.25 \mathrm{~mm}$ sodium octyl-sulfate.

dogenous catecholamine, total catecholamine (norepinephrine and dopamine) content was measured using HPLC with electrochemical detection, and used to calculate the ratio of endogenous 5-HT to catecholamine (in moles) in cultures grown with serum-free medium. For cultures grown with $\mathrm{CM}$, this ratio was 0.023 -at least 12 -fold higher than ratios obtained for cultures grown in high $\mathrm{K}^{+}$or $\mathrm{L}-15 \mathrm{CO}_{2}$ (Table 1$)$.

\section{Immunocytochemical staining}

To determine whether the neurons were heterogeneous with respect to 5-HT levels, cultures were examined with immunocytochemical staining, using the peroxidase-antiperoxidase technique (Fig. 3 and Table 1). When the neurons were grown in the presence of rat serum ( 3 platings), many neuronal processes contained 5-HT-like immunoreactive material. The number of stained processes was highest in high- $\mathrm{K}^{+}$cultures, lower in $\mathrm{L}-15 \mathrm{CO}_{2}$ cultures, and lowest in cultures grown in CM (Fig. 3). The total number of processes in these growth conditions is probably similar, because total protein and total lipid phosphate are not significantly different with or without CM (Patterson and Chun, 1977a). Few cell bodies (0-2.0\%) contained 5-HT-like immunoreactive material unless CM was present in the growth medium. The proportion of cell bodies that stained above background varied between 43 and $72 \%$ in cultures grown with different preparations of $\mathrm{CM}$, as might be expected, given prior observations that different batches of $\mathrm{CM}$ are not equally effective in promoting cholinergic behavior, and evidence that unpurified CM is a complex mixture of molecules released by cardiac myocytes and fibroblasts (Weber, 1981; Fukada, 1985). When neurons were grown in serum-free medium (3 platings), only cultures grown with CM possessed 5-HT-positive processes and somata (Fig. 3 and Table 1). Preadsorption of the antibody with 5-HT conjugated to BSA prevented the staining.

\section{Synthesis}

There are 2 potential sources of neuronal 5-HT: synthesis and uptake from the growth medium (see below). To study the for- mer, cultures were examined for synthesis and accumulation of ${ }^{3} \mathrm{H}-5$-HT from ${ }^{3} \mathrm{H}$-tryptophan, using HPLC with electrochemical detection and fraction collection. After 17-18 hr incubations at $36^{\circ} \mathrm{C}$ in $3.7-4.0 \mu \mathrm{M}{ }^{3} \mathrm{H}$-tryptophan and $25 \mu \mathrm{M}$ pargyline (to block 5-HT degradation), significant amounts of radioactivity coeluting with 5-HT (peak retention time, 28.15 min; Fig. 4) could be detected in cultures grown in CM (4 platings), but not in cultures grown in L-15 $\mathrm{CO}_{2}$ or high $\mathrm{K}^{+}$(2 platings), with or without rat serum (Table 1). Radioactive tryptophan eluted with a retention time greater than $34.0 \mathrm{~min}$. Cultures grown in $\mathrm{CM}$ synthesized an average of $0.18 \mathrm{fmol}{ }^{3} \mathrm{H}-5$-HT per neuron during the 17-18 hr incubation, while in cultures grown in $\mathrm{L}-15 \mathrm{CO}_{2}$ or high $\mathrm{K}^{+}$synthesis was less than 0.008 fmol ${ }^{3} \mathrm{H}-5-\mathrm{HT}$ per neuron (Table 1). In the absence of the MAO inhibitor pargyline, cultures grown in CM accumulated 4-8-fold less ${ }^{3} \mathrm{H}-5$-HT (Table 1).

In vivo, the presence of 5-HT in sympathetic ganglia has been attributed to small, intensely fluorescent (SIF) interneurons (see Discussion). It was therefore of interest to compare 5-HT synthesis in cultures that contained enzymatically dissociated neurons, including a few SIF cells, with cultures that contained mechanically dissociated neurons. Doupe et al. (1985) reported that the latter rarely contained SIF cells. This was confirmed by glyoxylic acid-induced fluorescence (data not shown). In 11 cultures that contained enzymatically dissociated neurons, a total of 3 brightly fluorescent cells were observed, while in 4 cultures that contained mechanically dissociated neurons, no brightly fluorescent cells were observed. These 2 types of cultures synthesized comparable amounts of ${ }^{3} \mathrm{H}-5-\mathrm{HT}$ (data not shown). Thus, there seems no reason to doubt that cultured principal neurons can synthesize 5-HT.

\section{Uptake}

Another potential source of 5-HT was the culture medium that contained 5\% rat serum. Our rat serum contained 5-10 $\mu \mathrm{M}$ 5-HT, as measured by HPLC with electrochemical detection; thus, the concentration of 5-HT in the culture medium was $0.25-0.50 \mu \mathrm{M}$. Levels of $5-\mathrm{HT}$ in the cultures were highest just after replacing the culture medium with fresh medium (feeding), and declined to very low levels over a period of several days (Fig. 5), consistent with 5-HT uptake and metabolism. If the cultures were incubated with fresh medium for $1 \mathrm{hr}$ at $37^{\circ} \mathrm{C}$ when 5-HT levels were low, their 5-HT levels rose 10-20-fold (data not shown). Furthermore, when the cultures were grown in serum-free medium (i.e., without exogenous 5-HT; $<0.07$ nM 5-HT plus 5-hydroxytryptophan; 3 platings), high $\mathrm{K}^{+}$and $\mathrm{L}-15 \mathrm{CO}_{2}$ cultures no longer contained detectable amounts of 5-HT, while cultures grown in CM did, presumably as a consequence of synthesis and accumulation from tryptophan.

\section{$C a^{2+}$-dependent release of 5-HT}

The 5-HT present in the cultures was releasable in a $\mathrm{Ca}^{2+}$-dependent manner. To evoke release of 5-HT from the cultures, we used high $\mathrm{K}^{+}(54 \mathrm{~mm})$ or veratridine $(75 \mu \mathrm{M})$. The presence of 5-HT in the incubation medium was then determined with HPLC and electrochemical detection. Incubation in high $\mathrm{K}^{+}$led to a large increase of 5-HT release over basal levels ( 2 platings); in the experiment shown in Figure $6\left(\mathrm{~L}-15 \mathrm{CO}_{2}\right.$ cultures), the increase was 6-fold. This release was $\mathrm{Ca}^{2+}$-dependent; in the presence of high-K ${ }^{+}$saline with high $\mathrm{Mg}^{2+} / 0 \mathrm{Ca}^{2+}$, there was no increase in 5-HT release. Approximately $17 \%$ of the total $5-\mathrm{HT}$ stored in this culture was released by a 5 min exposure to high 

High K+
$\mathrm{L}-15 \mathrm{CO}_{2}$
CM

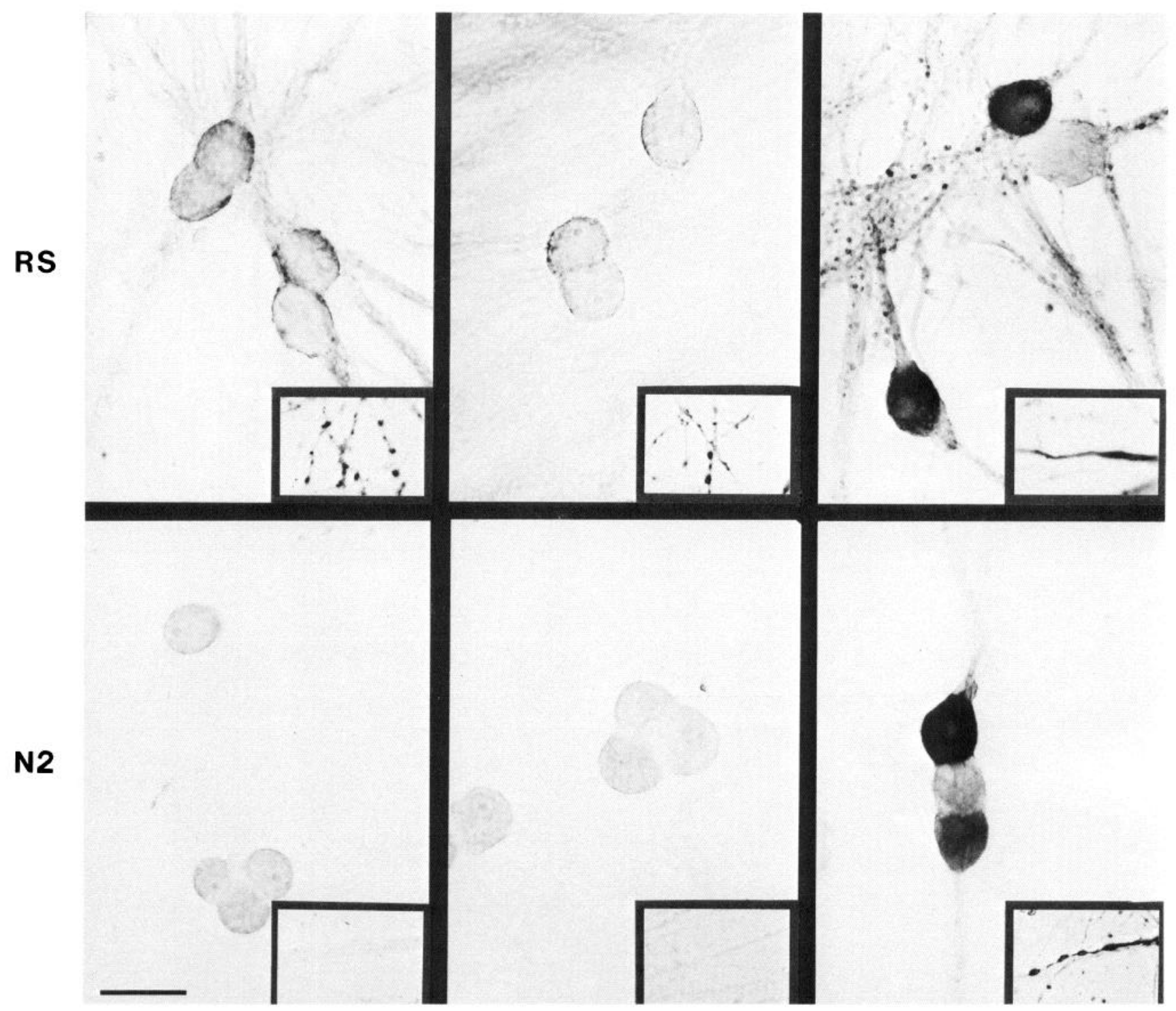

Figure 3. Serotonin-like immunoreactivity in sympathetic neuron cultures grown in high $\mathrm{K}^{+}, \mathrm{L}-15 \mathrm{CO}_{2}$, or $\mathrm{CM}$, with $(\mathrm{RS})$ or without $(\mathrm{N} 2) 5 \%$ rat serum, for 3 weeks. In cultures grown with rat serum, high- $\mathrm{K}^{+}$cultures contained many processes moderately stained for 5-HT-like immunoreactivity, while L-15 $\mathrm{CO}_{2}$ cultures contained fewer processes that were 5-HT-immunoreactive. Very few cell bodies stained above background levels unless $\mathrm{CM}$ had been present in the growth medium. In serum-free growth medium, stained processes were no longer present in high-K ${ }^{+}$or L-15 $\mathrm{CO}_{2}$ cultures, but many cell bodies and processes were still 5-HT-immunoreactive in CM cultures. Staining was eliminated by preadsorption of the primary antibody with 5 -HT conjugated to BSA. Calibration bar, $50 \mu \mathrm{m}$.

$\mathrm{K}^{+}$. A 5 min incubation in $75 \mu \mathrm{M}$ veratridine evoked release of $27 \%$ of stored 5-HT (Fig. 6). Again, this release was $\mathrm{Ca}^{2+}$-dependent; 5 -HT release fell to basal levels when $\mathrm{Mg}^{2+}$ was substituted for $\mathrm{Ca}^{2+}$ during incubation in veratridine.

\section{Do neurons exposed to 5-hydroxytryptophan acquire serotonergic function?}

In microculture, solitary neurons with adrenergic function could be induced to display NAE (nonadrenergic excitation of the myocytes) by loading them with the 5-HT precursor, 5-hydroxytryptophan, which itself has no detectable effect on the cardiac myocytes. One such case, a neuron with adrenergic, purinergic, and NAE function, is shown in Figure 7. In control solution, stimulation of the neuron produced an excitation of the cardiac myocytes (Fig. 7a). Addition of adrenergic and purinergic antagonists revealed an NAE effect (Fig. $7 b$ ). After 14 trials, the NAE effect ran down (Fig. 7c) and was restored by loading with 5-hydroxytryptophan (Fig. 7d). This restored NAE effect was at least partially sensitive to the 5-HT antagonist, gramine (Fig. 7e). Although the restored effect was similar in amplitude and time course to the original NAE effect, it is not known if the 2 effects were mediated by the same neurotransmitter. In attempts to load 7 other neurons in microculture, 3 loadable neurons all exhibited prior adrenergic function. The remaining 4 neurons were not loadable and displayed no detectable prior adrenergic function (data not shown). 


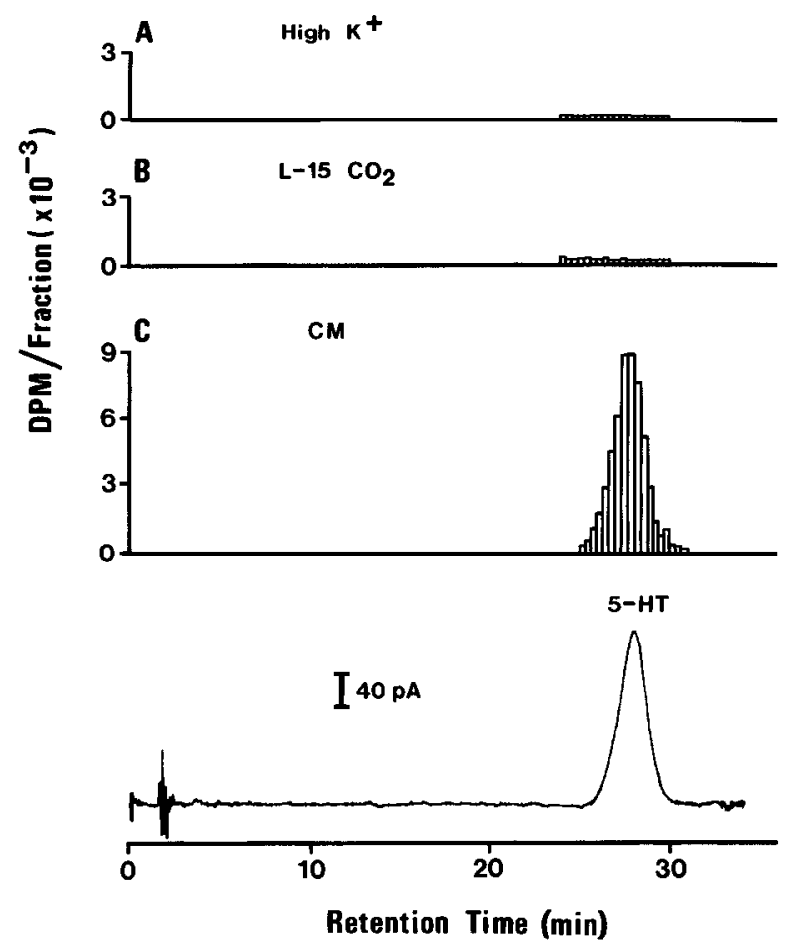

Figure 4. Synthesis and accumulation of ${ }^{3} \mathrm{H}-5-\mathrm{HT}$ from ${ }^{3} \mathrm{H}$-tryptophan in sympathetic neuron cultures grown with $C M$ in serum-free medium but not in high-K $K^{+}$or $L-15 \mathrm{CO}_{2}$ medium ( $21 \mathrm{~d}$ in vitro). Sister cultures, each containing approximately 2000 neurons, were incubated for $17 \mathrm{hr}$ in $4.0 \mu \mathrm{M}{ }^{3} \mathrm{H}$-tryptophan with $25 \mu \mathrm{M}$ pargyline. Culture extracts were injected onto the HPLC, and $0.4 \mathrm{ml}(20 \mathrm{sec})$ fractions were collected and counted (upper 3 panels). For comparison, authentic 5-HT (5.2 pmol) was injected (bottom panel), resulting in a peak at $28.15 \mathrm{~min}$. A peak of radioactivity, coeluting with authentic 5-HT, was present only in cultures grown in CM. The running buffer contained $0.1 \mathrm{M} \mathrm{NaH} \mathrm{PO}_{4}$, $2.5 \%$ (vol/vol) methanol, and $0.25 \mathrm{~mm}$ sodium octyl-sulfate.

\section{Discussion}

We have demonstrated that principal neurons derived from the SCG of the newborn rat synthesize, take up, store, and release 5-HT in culture, consistent with a transmitter role. Mains and Patterson (1973) did not detect synthesis and accumulation of

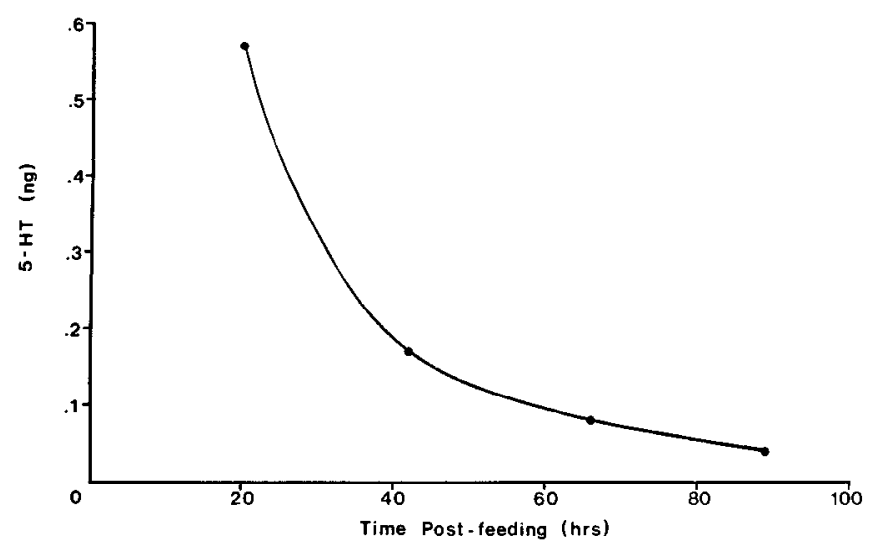

Figure 5. Decline of 5-HT levels in cultures with time after feeding. Four sister cultures grown in $\mathrm{L}-15 \mathrm{CO}_{2}$ medium with $5 \%$ rat serum for 3 weeks were fed fresh culture medium at time 0 . Each point represents the amount of 5-HT extracted from a single culture, as determined by HPLC with electrochemical detection.

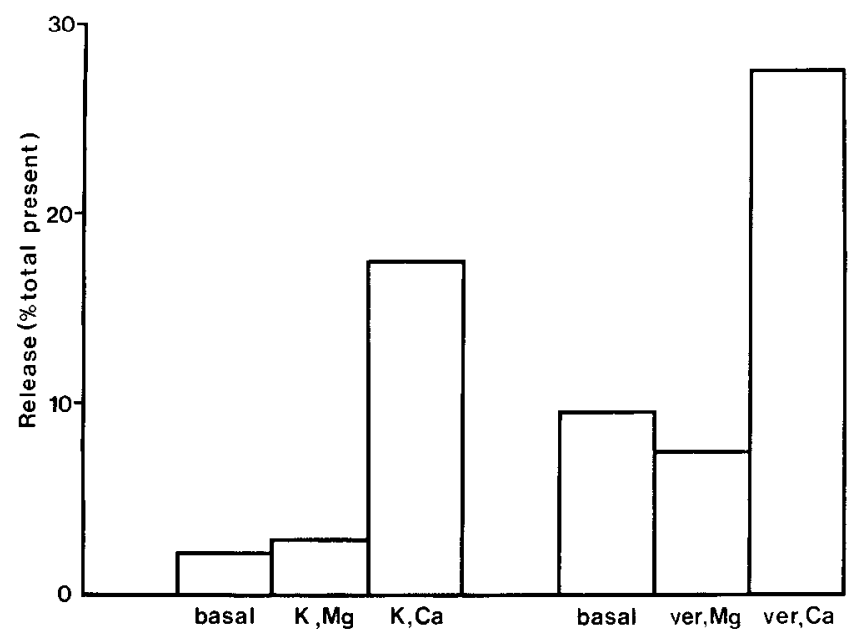

Figure 6. $\mathrm{Ca}^{2+}$-dependent release of 5-HT from sympathetic neuron cultures grown in $\mathrm{L}-15 \mathrm{CO}_{2}$ medium with $5 \%$ rat serum for $15 \mathrm{~d}$ (release evoked by high $\mathrm{K}^{+}$) or $33 \mathrm{~d}$ (release evoked by veratridine). Release is expressed as the percentage of total (released + extracted) 5-HT in 1 culture, as measured by HPLC with electrochemical detection. Cultures were stimulated with either $54 \mathrm{mM} \mathrm{K}^{+}(K$, left bars) or $75 \mu \mathrm{M}$ veratridine (ver, right bars) for $5 \mathrm{~min}$ at room temperature, in the presence of $\mathrm{Ca}^{2+}$, without $\mathrm{Mg}^{2+}(\mathrm{Ca})$ or in the presence of $\mathrm{Mg}^{2+}$, without $\mathrm{Ca}^{2+}(\mathrm{Mg})$.

radioactive 5-HT from ${ }^{3} \mathrm{H}$-tryptophan in cultures of SCG neurons grown without $\mathrm{CM}$. Similarly, we did not detect 5-HT synthesis and accumulation in cultures grown in L-15 $\mathrm{CO}_{2}$ or high $\mathrm{K}^{+}$. CM in the growth medium was required for the detection of 5-HT synthesis and accumulation. Since the rat SCG in vivo contains 5-HT and tryptophan hydroxylase (Liuzzi et al., 1977), which have been attributed to SIF cells in the ganglion (e.g., Verhofstad et al., 1981), it was important to determine whether a residual population of SIF cells in the cultures was responsible. This was unlikely, since cultures obtained from mechanically dissociated ganglia grown in NGF and in the absence of glucocorticoid for more than 3 weeks rarely contain SIF cells (Doupe et al., 1985, and personal observations with glyoxylic acid-induced fluorescence). These cultures synthesized amounts of 5-HT comparable to those of cultures obtained from enzymatically dissociated ganglia; the latter contained a few SIF cells. Moreover, the immunohistochemical staining of the principal neuron cell bodies for 5-HT appeared to represent endogenously synthesized 5-HT; when cultures were grown with $\mathrm{CM}$ in serum-free medium to eliminate uptake of 5-HT from serum, the proportion of cell bodies containing 5-HT-like immunoreactivity was comparable to that in sister cultures grown in serum. However, staining of processes present in cultures grown with serum in $\mathrm{L}-15 \mathrm{CO}_{2}$ or high $\mathrm{K}^{+}$was no longer present with serum-free $\mathrm{L}-15 \mathrm{CO}_{2}$ or high $\mathrm{K}^{+}$. These cultures also no longer contained detectable amounts of 5-HT, as assayed with HPLC and electrochemical detection. Thus, staining of processes in cultures grown in $\mathrm{L}-15 \mathrm{CO}_{2}$ or high $\mathrm{K}^{+}$was attributable to uptake of 5-HT from the growth medium, while staining in the cell bodies, after growth in CM, apparently represented 5-HT synthesis. Since many large principal neurons grown with $\mathrm{CM}$ in serum-free medium stained above background levels, we see no reason to doubt that these neurons synthesized and stored 5-HT. This is the first evidence known to us that sympathetic principal neurons can synthesize 5-HT. It is clearly of interest to investigate whether induction of $5-\mathrm{HT}$ synthesis by $\mathrm{CM}$ is 
a

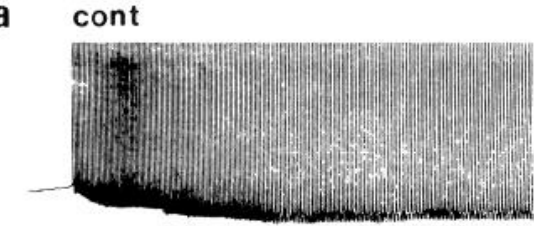

$\underbrace{1}_{1}$ b

aten/phentol + 8SPT

C

rundown
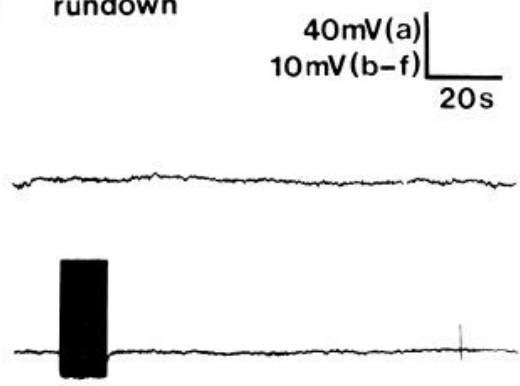

$d-f$ : after 5 HTP loading

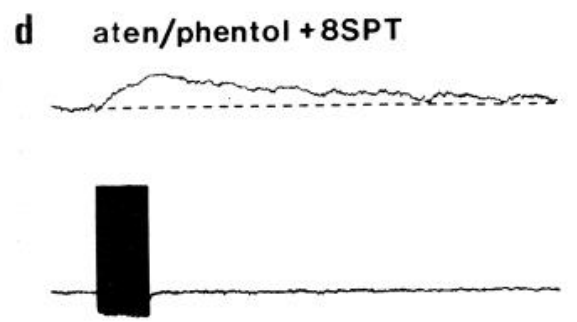

e

aten/phentol + 8SPT + Gr

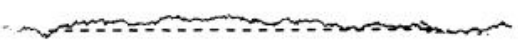

f aten/phentol+8SPT
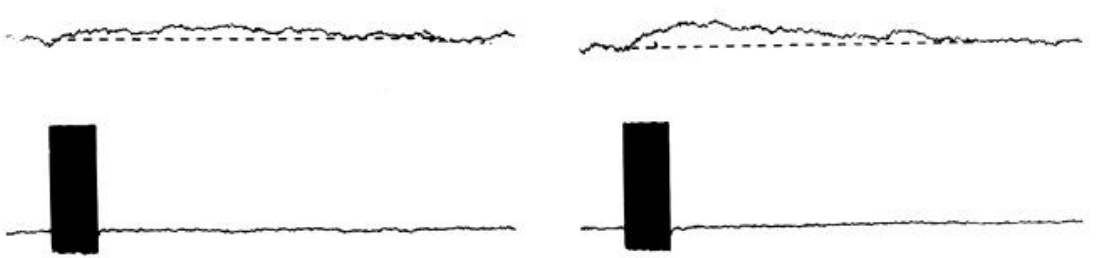

Figure 7. Functional loading with 5-hydroxytryptophan in microculture. The neonate-derived neuron had been in culture for $55 \mathrm{~d}$, in the presence of $5 \%$ rat serum. For the first $25 \mathrm{~d}$, it was in high- $\mathrm{K}^{+}$culture medium, which favors retention of adrenergic function. $a$, In control (cont) solution, stimulation $(20 \mathrm{~Hz})$ of the neuron produced an excitation of the cardiac myocytes. $b$, Addition of $10 \mu \mathrm{M}$ atenolol $($ aten $)$, $0.1 \mu \mathrm{M}$ phentolamine (phentol), and $10 \mu \mathrm{M} 8$-(p-sulfophenyl)-theophylline (8SPT) blocked much of the excitation, leaving an NAE effect. $c$, This effect ran down after 14 trials (2-20 min between trials; rundown), and $(d)$ was restored after $15 \mathrm{~min}$ of loading the neuron with $100 \mu \mathrm{M}$ 5-hydroxytryptophan. In $c$ and $d$, atenolol, phentolamine and 8-( $p$-sulfophenyl)-theophylline were still present. In $e, 1 \mu \mathrm{M}$ gramine (Gr) was added to the adrenergic and purinergic antagonists, blocking much of the restored NAE effect. $f$, This block was substantially reversed upon washout of the gramine. (The increase in noise level in $c-f$ compared to $b$ was probably due to an increase in the impedance of the microelectrode.)

due to the factor that induces cholinergic status (see Fukada, $1980,1985)$ or to another agent.

Uptake of 5-HT from serum in the medium is an important source of the neuronal 5-HT in culture. Levels of 5-HT achieved by uptake are an order of magnitude greater than those achieved by synthesis. In vivo, sympathetic neurons are not normally exposed to serum. However, adrenergic nerves can accumulate and then secrete exogenous 5-HT (e.g., Thoa et al., 1969) or 5 -HT released from aggregating platelets (Cohen, 1985) or pinealocytes (Axelrod, 1974; Jaim-Etcheverry and Zieher, 1980). It is imaginable that the terminals of SCG neurons are exposed to 5 -HT released by mast cells in the target tissues. Thus, $5-\mathrm{HT}$ uptake from extraneuronal sources other than pinealocytes may occasionally occur in vivo as in cultured neurons.

Some neurons in microculture release a substance that is blocked by 5 -HT antagonists (see the preceding paper by Matsumoto et al., 1987). It is of interest to determine whether the source of 5-HT in these neurons is synthesis and/or uptake from the growth medium. This is being examined by first assaying a neuron with respect to serotonergic function, and then staining that neuron for 5-HT. The evidence discussed above implies that if the soma is immunoreactive for 5-HT, the neuron synthesized 5-HT, but that if only the processes stain, the source of 5-HT is likely to have been uptake from the serum in the growth medium.

The percentage of NAE plus that of S (serotonergic function) in figure 4 of Matsumoto et al. (1987)-12\%-is much lower than the proportion of cell bodies that are immunoreactive for 5-HT after growth in CM. There are several possible causes of this discrepancy. Neurons grown with CM may not be identical to those grown with cardiac myocytes in microculture with respect to serotonergic function. Moreover, immunocytochemical staining may be a more sensitive method than a bioassay involving cardiac myocytes, a target tissue that is relatively insensitive to 5-HT (compared to the action of norepinephrine and acetylcholine on this tissue, and compared to the action of 5-HT on vas deferens smooth muscle; see Matsumoto et al., 1987). Furthermore, the former technique gives a measurement of the total pool of 5-HT, while the latter only gives a measure of the releasable pool, so that a direct comparison may not be appropriate. In addition, the releasable pool may be significantly depleted with successive stimulus trains, resulting in a progressive decline in the cardiac myocytes' response. Thus, we may have reduced the probability of detecting NAE and/or serotonergic function by presenting many stimulus trains to a neuron before examining it for these functions.

The microcultured neurons that displayed serotonergic function also exhibited adrenergic, or adrenergic and purinergic, function. As noted above, a small sample of neurons with adrenergic function that were exposed to 5-hydroxytryptophan subsequently evoked an NAE effect blockable by 5-HT-receptor antagonists, presumably due to release of 5-HT. In contrast, a few neurons that lacked adrenergic function were not loadable by this procedure. Different levels of aromatic amino acid decarboxylase (the enzyme that converts 5-hydroxytryptophan to 5-HT), plasma membrane uptake, or vesicular storage might account for the inability of these cholinergic neurons to load with 5-hydroxytryptophan. The results of these preliminary 
electrophysiological experiments are consistent with the idea that adrenergic function is required for a neuron to take up $5 \mathrm{Ht}$ from the medium, store, and release it in physiologically detectable amounts.

It is of interest, in this connection, that no cholinergic/serotonergic or purinergic/serotonergic neurons have yet been encountered (Matsumoto et al., 1987); among the microcultured neurons that exerted NAE effects without prior loading with 5-hydroxytryptophan, serotonergic function has been coexpressed with adrenergic function thus far ( 3 cases in which the neuron was fully characterized; these are included in fig. 4 of the preceding paper). Again, this is consistent with the idea that vesicular storage and release of 5-HT in these cultured principal neurons is dependent on the presence of adrenergic function. Whether or not neurons with adrenergic/cholinergic function can also express serotonergic function remains to be seen.

The present work shows that conditioned medium, which contains a factor (Fukada, 1980, 1985; Weber, 1981) that enhances expression of cholinergic properties and diminishes expression of adrenergic properties (Patterson and Chun, 1977a; Landis, 1980; Wolinsky and Patterson, 1983; Potter et al., 1986), also promotes synthesis of 5-HT. This seems dissonant with the preliminary physiological evidence just discussed-that serotonergic function is dependent on adrenergic function. If the cholinergic-inducing factor in $\mathrm{CM}$ is also responsible for the presence of serotonergic properties, then this factor has 2 seemingly conflicting effects: lowering the neuron's capacity to secrete 5-HT (via the adrenergic vesicles), while promoting its capacity to synthesize 5-HT. Another obvious possibility is that the conditioned medium fed to our cultures contained 2 agents, the cholinergic-inducing factor and a second factor that allowed expression of serotonergic properties, and that in our cultures these agents acted simultaneously on the neurons, with the observed conflicting effects. It is clearly of interest to determine whether neurons grown with $\mathrm{CM}$ that are strongly immunoreactive for 5-HT (as in the lower-right panel of Fig. 3) and presumably synthesize 5 -HT always simultaneously display at least moderate adrenergic function. This is being checked in microcultures by assaying the physiological function(s) of a neuron and then its immunoreactivity.

In the autonomic nervous system, 5-HT is known to be an endogenous transmitter of principal neurons only in the enteric plexuses (Gershon et al., 1977; Wood and Mayer, 1979; Costa et al., 1982), where 5-HT synthesis has been demonstrated (Dreyfus et al., 1977). However, there are several reports that autonomic nerve terminals can take up and release exogenous 5-HT, e.g., in the pancreas (Koevary et al., 1983), vas deferens (Thoa et al., 1969), and blood vessels (Kawasaki and Takasaki, 1984). In the pineal gland, nerve terminals from the SCG take up and store 5-HT that is synthesized and released by the pinealocytes (Axelrod, 1974; Jaim-Etcheverry and Zieher, 1980). The presence of 5-HT and tryptophan hydroxylase has been demonstrated in the adult rat SCG in vivo (Liuzzi et al., 1977), and attributed to the SIF cells that contain 5-HT-like immunoreactivity (Verhofstad et al., 1981). Recently, however, it has been shown that during the first 5 postnatal weeks, some of the principal neurons of this ganglion transiently contain 5-HT immunoreactivity (Häppölä et al., 1986). Our experiments show that in culture, after growth in CM, some postnatal principal neurons synthesize and accumulate 5-HT. It will be interesting to examine the development and plasticity of serotonergic prop- erties in vitro, both in mass cultures and in single identified neurons in microculture, as has been done with adrenergic and cholinergic properties (e.g., Johnson et al., 1976; Patterson and Chun, 1977b; Landis, 1980; Potter et al., 1986).

\section{References}

Axelrod, J. (1974) The pineal gland: A neurochemical transducer. Science 184: 1341-1348.

Bottenstein, J. E., and G. H. Sato (1979) Growth of a rat neuroblastoma cell line in serum-free supplemented medium. Proc. Natl. Acad. Sci. USA 76: 514-517.

Cohen, R. A. (1985) Platelet-induced coronary contractions due to accumulation of the false transmitter, 5-hydroxytryptamine. J. Clin. Invest. 75: 286-292.

Costa, M., J. B. Furness, A. C. Cuello, A. A. J. Verhofstad, H. W. J. Steinbusch, and R. P. Elde (1982) Neurons with 5-hydroxytryptamine-like immunoreactivity in the enteric nervous system: Their visualization and reactions to drug treatment. Neuroscience $7: 351-$ 363.

Doupe, A. J., P. H. Patterson, and S. C. Landis (1985) Small intensely fluorescent cells in culture: Role of glucocorticoids and growth factors in their development and interconversions with other neural crest derivatives. J. Neurosci. 5: 2143-2160.

Dreyfus, C. F., M. B. Bornstein, and M. D. Gershon (1977) Synthesis of serotonin by neurons of the myenteric plexus in situ and in organotypic tissue culture. Brain Res. 128: 125-139.

Fukada, K. (1980) Hormonal control of neurotransmitter choice in sympathetic neurone cultures. Nature 287: 553-555.

Fukada, K. (1985) Purification and partial characterization of a cholincrgic neuronal differentiation factor. Proc. Natl. Acad. Sci. USA 82: 8795-8799.

Furshpan, E. J., D. D. Potter, and S. C. Landis (1982) On the transmitter repertoire of sympathetic neurons in culture. Harvey Lect. 76 : 149-191.

Furshpan, E. J., S. C. Landis, S. G. Matsumoto, and D. D. Potter (1986a) Synaptic functions in rat sympathetic neurons in microcultures. I. Secretion of norepinephrine and acetylcholine. J. Neurosci. 6: 1061-1079.

Furshpan, E. J., D. D. Potter, and S. G. Matsumoto (1986b) Synaptic functions in rat sympathetic neurons in microcultures. III. A purinergic effect on cardiac myocytes. J. Neurosci. 6: 1099-1107.

Gershon, M. D., C. F. Dreyfus, V. M. Pickel, T. H. Joh, and D. J. Reis (1977) Serotonergic neurons in the peripheral nervous system: Identification in gut by immunohistochemical localization of tryptophan hydroxylase. Proc. Natl. Acad. Sci. USA 74: 3086-3089.

Häppölä, O., H. Päivärinta, S. Soinila, and H. Steinbusch (1986) Preand postnatal development of 5-hydroxytryptamine-immunoreactive cells in the superior cervical ganglion of the rat. J. Autonom. Nerv. Syst. 15: 21-31.

Hawrot, E., and P. H. Patterson (1979) Long-term culture of dissociated sympathetic neurons. Methods Enzymol. 58: 574-584.

Jaim-Etcheverry, G., and L. M. Zieher (1980) Stimulation-depletion of serotonin and noradrenaline from vesicles of sympathetic nerves in the pineal gland of the rat. Cell Tissue Res. 207: 13-20.

Johnson, M., D. Ross, M. Myers, R. Rees, R. Bunge, E. Wakshull, and H. Burton (1976) Synaptic vesicle cytochemistry changes when cultured sympathetic neurones develop cholinergic interactions. Nature 262: $308-310$.

Kawasaki, H., and K. Takasaki (1984) Vasoconstrictor response induced by 5-hydroxytryptamine released from vascular adrenergic nerves by periarterial nerve stimulation. J. Pharmacol. Exp. Ther. 229: 816-822.

Koevary, S. B., E. C. Azmitia, and R. C. McEvoy (1983) Rat pancreatic serotonergic nerves: Morphologic, pharmacologic, and physiologic studies. Brain Res. 265: 328-332.

Landis, S. C. (1980) Developmental changes in neurotransmitter properties of dissociated sympathetic neurons: A cytochemical study of the effects of medium. Dev. Biol. 77: 349-361.

Liuzzi, A., F. H. Foppen, J. M. Saavedra, R. Levi-Montalcini, and I. J. Kopin (1977) Gas chromatographic-mass spectrometric assay of serotonin in rat superior cervical ganglia. Effects of nerve growth factor and 6-hydroxydopamine. Brain Res. 133: 354-357.

Mains, R. E., and P. H. Patterson (1973) Primary cultures of disso- 
ciated sympathetic neurons. I. Establishment of long-term growth in culture and studies of differentiated properties. J. Cell Biol. 59: 329345.

Matsumoto, S. G., D. Sah, D. D. Potter, and E. J. Furshpan (1987) Synaptic functions in rat sympathetic neurons in microcultures. IV. Nonadrenergic excitation of cardiac myocytes and the variety of multiple-transmitter states. J. Neurosci. 7: 380-390.

Patterson, P. H., and L. L. Y. Chun (1977a) The induction of acetylcholine synthesis in primary cultures of dissociated rat sympathetic neurons. I. Effects of conditioned medium. Dev. Biol. 56: 263-280.

Patterson, P. H., and L. L. Y. Chun (1977b) The induction of acetylcholine synthesis in primary cultures of dissociated rat sympathetic neurons. II. Developmental aspects. Dev. Biol. 60: 473-481.

Potter, D. D., S. C. Landis, S. G. Matsumoto, and E. J. Furshpan (1986) Synaptic functions in rat sympathetic neurons in microcultures. II. Adrenergic/cholinergic dual status and plasticity. J. Neurosci. 6: 10801098.

Thoa, N. B., D. Eccleston, and J. Axelrod (1969) The accumulation of ${ }^{14} \mathrm{C}$-serotonin in the guinea-pig vas deferens. J. Pharmacol. Exp. Ther. 169: 68-73.
Verhofstad, A. A. J., H. W. M. Steinbusch, B. Penke, J. Varga, and H. W. J. Joosten (1981) Serotonin-immunoreactive cells in the superior cervical ganglion of the rat: Evidence for the existence of separate serotonin and catecholamine-containing small ganglionic cells. Brain Res. 212: 39-49.

Walicke, P. A., R. B. Campenot, and P. H. Patterson (1977) Determination of transmitter function by neuronal activity. Proc. Natl. Acad. Sci. USA 74: 5767-5771.

Weber, M. J. (1981) A diffusible factor responsible for the determination of cholinergic functions in cultured sympathetic neurons. Partial purification and characterization. J. Biol. Chem. 256: 3447-3453.

Wolinsky, E., and P.H. Patterson (1983) Tyrosine hydroxylase activity decreases with induction of cholinergic properties in cultured sympathetic neurons. J. Neurosci. 3: 1495-1500.

Wolinsky, E., S. C. Landis, and P. H. Patterson (1985) Expression of noradrenergic and cholinergic traits by sympathetic neurons cultured without serum. J. Neurosci. 5: 1497-1508.

Wood, J. D., and C. J. Mayer (1979) Serotonergic activation of tonictype enteric neurons in guinea pig small bowel. J. Neurophysiol. 42: 582-593. 